\title{
The Impacts of Various Media on the Electronic Spectrum of Aniline Violet
}

\section{Sokaina Hemdan}

Department of Chemistry, Factually of Science and Art El Marj, Benghazi University, El Marj, Libya

E-mail: Sukains_h@yahoo.com

\section{Asma Al Jebaly}

Department of Chemistry, Factually of Science and Art El Marj, Benghazi University, El Marj, Libya

\section{E-mail: nnn616@Ymail.com}

\section{Fatma Ali}

Department of Chemistry, Factually of Science and Art El Marj, Benghazi University, El Marj, Libya

E-mail: Fatma198573@yahoo.com

\begin{abstract}
The solvent impact can be decided by Solvent polarity scales, a solvatochromic parameter that has a distinctive position of UV-Visible absorption band within the extend between 250 and $700 \mathrm{~nm}$. The spectral characteristics of Aniline Violet in several solvents at room temperature were analyzed which is that the point of considering the impact of solvents on the absorption spectra of this cationic dye in organic solvent of distinctive characters. The solvent impacts on the wavenumber of the absorption band maxima $\left(v_{\max }\right)$ were talked about utilizing the taking after solvent parameters, refractive index, $\mathrm{n}$, relative permittivity, $\varepsilon$ and therefore the empirical solvent polarity $E_{\mathrm{T}}(30),\left(\pi^{*}, \alpha\right.$ and $\left.\beta\right)$ and (SA, SB, SP and SPd). The solute-solvent interactions were decided on the premise of multilinear solvation energy relationships concept.
\end{abstract}


The fitting coefficients gotten from this analysis allowed us to estimate the contribution of each type of interactions to the total spectral shifts in solution. The set up dependences between $v_{\max }$ and the solvent parameters emphasize that the visible band of the examined molecule is influenced by both non-specific and specific solute-solvent interactions. The results appeared the solvent polarizability has major impact on the spectral shift instead of hydrogen bonding accepting ability. Catalan strategy show higher acceptable correlation than Kamlet-Taft methodology and Katritzky methodology. The dissociation constant $\mathrm{pKa}$ and the isosbestic point of the explored compound were shown the presence of the individual predominate ionic species was assigned by constructing distribution charts at diverse $\mathrm{pH}$ ranges. The results showed that the relative permittivity constant, $\varepsilon$, is important factor affecting on the magnitude of the dissociation constant beside the hydrogen bonding of the solvent.

Keywords: Negative solvatochromism; Dissociation Constant, Katritzky, Kamlet-Taft and Catalán solvatochromic models; UV-Visible Spectrum.

\section{Introduction}

Aniline violet $(A V)$, could be a species of tri-phenyl methane dye, with one dimethylamino group on each phenyl ring.[1], too called as basic violet 3 , gentian violet, crystal violet and methyl violet $10 \mathrm{~B}$, Figure(1), is one amongst the foremost important indicators can act like exceptionally powerless base and play as an inferior role as indicator in titration in aqueous solution. However, this indicator is incredibly important for the endpoint indication of titrations in non-aqueous media.[2] This dye is employed as biological stains, in medicine and as a dye for silk, wood, cosmetics, and food.[3]

Solvent impacts can play a critical part in numerous chemical and physical behaviors such as hydrogen bonding and tautomerism in solutions.[4] Solvatochromism could be a effective tool to explore the physical-chemical properties of molecules.[5] The solvent dependent phenomena originate from either nonspecific (dispersion and dipole forces) or specific (e.g .hydrogen bonding) solute--solvent interactions. 
The solvent impact can be assessed by implies of solvent polarity scale and solvatochromic parameters.[6-7] A few spectroscopic solvent polarity parameters have been inferred from standard solvatochromic compounds absorbing radiation in corresponding spectral ranges.[7-9] The positions and/or intensities of the absorption bands of the solvatochromic dyes within the visible region undergo remarkable changes with a subtle change in the properties of solvents.[10]The specialist spectral changes of such dyes in different environments are often exploited to investigate intrinsic properties of a given medium. The solvatochromic dyes are thus important for a huge number of practical applications.[11]

The esteem of the acid dissociation constant $(\mathrm{pKa})$ is an important parameter that shows the degree of ionization of molecules in solution at diverse $\mathrm{pH}$ values. Numerous chemical, physical and biological properties of normal and manufactured compounds are administered by the interactions of acidic and basic groups. In such compounds, the pKa controls numerous aspects of metabolism and even transport across membranes; therefore, its study is of significant interest in biology, pharmaceutics, medicine, and numerous other scientific fields. [12] Beside, the examination impact of organic solvents on the acid dissociation constant play very important role as result as different properties control in the magnitude of pKa.[13-14]

This present work, was planned to consider the impact of non-specific and specific solute-solvent interactions on UV-Visible absorption spectra of Aniline Violet, Figure 1, The electronic transition mechanisms and solvatochromic behaviour of the examined molecule have been decided by utilizing three distinctive linear solvation energy relationships (LSER), the Katritzky, the Kamlet-Abboud-Taft and Catalán solvatochromic strategies. The spectral characteristics of Aniline Violet in various solvents at room temperature were analyzed utilizing IBM-SPSS (a program of a statistical package of social sciences version 19) to decide coefficients by numerous linear regression techniques. The physical parameters of the solvents utilized are arranged in, Tables(1,2): relative permittivity, $\varepsilon$, refractive index ,n, the ReichardtDimroth $E_{T(30)}$ [5] and corresponding Kamlet-Taft [16]and Catalan[17] solvent 
parameters. The solvents are organized with an increasing their solvent polarity. Additionally, the UV-Vis absorption spectra of Aniline Violet were explored in watery buffer solutions of diverse $\mathrm{pH}$ values within the run 2-12 and utilized for computing the dissociation constant $(\mathrm{pKa})$. The individual ionic species are overwhelming have been decided. On other hand, The impact of Co-solvent on the acid dissociation constant magnitude have been assessed.

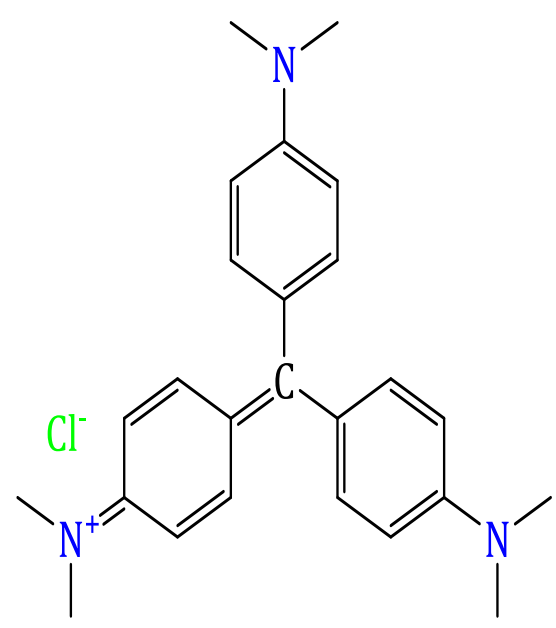

Figure 1: Chemical Formula of Aniline Violet

\section{Experimental and methods}

\subsection{Reagents and Material}

The Aniline Violet and beginning Material utilized in this work were gotten from Sigma-Aldrich , BDH and Fluka companies. The solvents were of HPLC grade and have been utilized without encourage decontamination. All solutions were prepared with deionized and $\mathrm{CO}_{2}$-free water . The universal buffer utilized in this work was prepared by mixing $0.04 \mathrm{M}$ of $\mathrm{H}_{3} \mathrm{BO}_{3}, \mathrm{H}_{3} \mathrm{PO}_{4}$ and glacial $\mathrm{CH}_{3} \mathrm{OOH}$ acids and including the desired volume of $0.2 \mathrm{M} \mathrm{NaOH}\left(\mathrm{CO}_{2}\right.$ free $)$ to grant the specified $\mathrm{pH}$. The ionic strength of the considered solution was balanced by including $0.5 \mathrm{M}$ solution of $\mathrm{KCl}$.

\subsection{Procedure}

The UV/Vis absorption spectral estimations were recorded within the appropriate solvent with CECIL-CE 7400(S.n.146368, England) UV-Visible Spectrophotometer model cell, covering the wavelength extend $250-700 \mathrm{~nm}$ with a $1-\mathrm{cm}$ path length quartz cell was utilized for UV-Vis spectra acquisition at room temperature $\left(\sim 20{ }^{\circ} \mathrm{C}\right)$. The solvents 
utilized within the present study namely, 1,4-dioxane, ethanol, n-Propanol, deionized water, Dimethylsulfoxide, Dimethylformamide, Acetone , n-Hexane, Toluene , Tetrachloromethane, Diethylether, Tetrahydrofuran, Ethylacetate, Acetic Acid, Methanol, CycloHexanone, Chlorobenzene, Anisole and Glycol were analytic grade and utilized without assist refinement. These solvents have distinctive polarity parameters mainly related to the refractive index (n) and dielectric constant ( $\varepsilon$ ) of each solvent.[5] The physical parameters of the solvents at $\sim 20{ }^{\circ} \mathrm{C}$ are collected in, Tables(1and 2). The dissociation constant of the aniline violet were decided by implies of the data obtained within the $\mathrm{pH}$ run 2-12. the $\mathrm{pH}$ magnitude measured by utilizing previously calibrated Precise pH-benchmeter Model PHS-3C .

\subsection{Data Treatment}

As said prior, solvent-dependent spectral shifts are a result of numerous specific (hydrogen bond) as well as nonspecific (ion-dipole, dipole-dipole, dipole-induced dipole, etc.) interactions between the solute and the solvent. For a comprehensive thought as to which inherent solvent property/properties influence(s) the spectral shifts of Aniline Violet, we have analyzed their solvatochromic data in light of Katritzky (KTZ), KamletTaft (KAT) and Catalan (CTN) multiparametric empirical relations. The multi-parameter solvent polarity scales can be utilized for characterization of the solvent-solute interactions, the impacts of solvents polarities on the spectroscopic behaviors are interpreted by means of linear solvation energy relationship (LSER) models that can be defined as Katritzky (Equation1) [15], Kamlet-Abboud-Taft (Equation 2)[16] and Catalán Equation's (Equation 3)[17]:

$$
v_{(\max )}=v_{(\max ) o}+a E_{T(30)}+b \frac{\varepsilon-1}{2 \varepsilon+1}+c \frac{n^{2}-1}{2 n^{2}+1}
$$

Where, $\mathrm{E}_{\mathrm{T}(30)}$ is experimental solvent polarity delicate to both solvent-solute hydrogen bonding and dipolar interactions and is related to $v_{\max }$, the wavenumber in $\mathrm{cm}^{-1}$ of the excitation maximum of the given solvent as follows: $E=2.895 \times 10^{-3} v_{\max }$ [18]. The dielectric function of Kirkwood, $f(\varepsilon)=\frac{\varepsilon-1}{2 \varepsilon+2}$ adequately represents the dipolar dielectric interactions and is a measure of the polarity of the solvent that depends on the dielectric 
constant of the solvent, $\varepsilon$ : [19] The function $f(n)=\frac{n^{2}-1}{2 n^{2}+1}$ has been introduced to account for the solute permanent dipole-solvent induced dipole interactions and is related to the refractive index of the solvent, $\mathrm{n}$ : [20]

$$
\begin{aligned}
& v_{(\max )}=v_{(\max ) o}+a \alpha+b \beta+s \pi * \\
& v_{(\max )}=v_{(\max ) o}+a S A+b S B+c S P+d S P d
\end{aligned}
$$

Where $\pi^{*}, \beta$, and $\alpha$ shows dipolarity/polarizability, hydrogen bond acceptor (HBA) basicity, and hydrogen bond donor (HBD) acidity,[16] individually. In Equation 3, the dipolarity /polarizability is characterized as (SPd and SP) the acidity of solvents as $\left(\mathrm{S}_{\mathrm{A}}\right)$, and basicity of solvents as $\left(\mathrm{S}_{\mathrm{B}}\right)$. [17] In Katritzky, Kamlet-Abboud-Taft and Catalán solvatochromic models, $v_{0}$ is the regression esteem of the solute property within the reference solvent. The remaining parameters (a, b, c, d and s coefficients) are gotten by utilizing multilinear regression analysis describing the sensitivity of the absorption maximum to the distinctive sorts of solvent-solute interactions. The partition of nonspecific solvent effects, term $\pi^{*}$ in Eq. (2), into two terms: dipolarity and polarizability, SPd and SP in Eq.(3), contributes to beneficial examination of the solvatochromism of the considered compound. The solvent parameters utilized in Eq. (2) and Eq. (3) are given, in Table(1)

Table (1): The Physical properties and Parameters of Solvents used in Correlation Equations( 2and3) .

\begin{tabular}{|c|c|c|c|c|c|c|c|c|c|c|}
\hline Solvents & $\mathbf{n}$ & $\boldsymbol{\varepsilon}$ & $\boldsymbol{\mu}$ & $\boldsymbol{\alpha}$ & $\boldsymbol{\beta}$ & $\boldsymbol{\pi}$ & $\boldsymbol{S A}$ & $\boldsymbol{S B}$ & $\boldsymbol{S P}$ & $\boldsymbol{S d}$ \\
\hline HX & 1.375 & 1.89 & 0.09 & 0.00 & 0.00 & -0.081 & 0.00 & 0.056 & 0.616 & 0.00 \\
\hline TCM & 1.460 & 2.24 & 0.00 & 0.00 & 0.00 & 0.28 & 0.00 & 0.044 & 0.768 & 0.00 \\
\hline TO & 1.497 & 2.38 & 0.31 & 0.00 & 0.12 & 0.54 & 0.00 & 0.128 & 0.782 & 0.284 \\
\hline DEtR & 1.353 & 4.34 & 1.15 & 0.00 & 0.47 & 0.27 & 0.00 & 0.562 & 0.617 & 0.385 \\
\hline DiX & 1.422 & 2.22 & 0.45 & 0.00 & 0.37 & 0.55 & 0.00 & 0.444 & 0.737 & 0.312 \\
\hline ANO & 1.518 & 4.30 & 1.36 & 0.00 & 0.22 & 0.73 & 0.084 & 0.299 & 0.820 & 0.543 \\
\hline THF & 1.407 & 7.58 & 1.63 & 0.00 & 0.55 & 0.58 & 0.00 & 0.591 & 0.714 & 0.634 \\
\hline
\end{tabular}




\begin{tabular}{|c|c|c|c|c|c|c|c|c|c|c|}
\hline CBN & 1.525 & 5.60 & 1.55 & 0.00 & 0.07 & 0.71 & 0.00 & 0.182 & 0.833 & 0.537 \\
\hline EtOAC & 1.372 & 6.02 & 1.78 & 0.00 & 0.45 & 0.55 & 0.00 & 0.542 & 0.656 & 0.603 \\
\hline CHN & 1.452 & 18.30 & 2.90 & 0.00 & 0.53 & 0.76 & 0.00 & 0.482 & 0.766 & 0.745 \\
\hline AC & 1.359 & 20.56 & 2.91 & 0.08 & 0.48 & 0.71 & 0.00 & 0.475 & 0.651 & 0.907 \\
\hline DMF & 1.427 & 38.25 & 3.86 & 0.00 & 0.69 & 0.88 & 0.031 & 0.613 & 0.759 & 0.977 \\
\hline DMSO & 1.478 & 47.24 & 3.96 & 0.00 & 0.76 & 1.00 & 0.072 & 0.647 & 0.830 & 1.000 \\
\hline PrOH & 1.386 & 20.80 & 1.68 & 0.84 & 0.85 & 0.52 & 0.367 & 0.782 & 0.658 & 0.748 \\
\hline ACA & 1.372 & 6.17 & 1.74 & 1.12 & 0.45 & 0.64 & 0.689 & 0.390 & 0.651 & 0.676 \\
\hline EtOH & 1.361 & 24.30 & 1.69 & 0.83 & 0.77 & 0.54 & 0.400 & 0.658 & 0.633 & 0.783 \\
\hline $\mathrm{MeOH}$ & 1.329 & 33.70 & 1.70 & 0.93 & 0.62 & 0.60 & 0.605 & 0.545 & 0.608 & 0.904 \\
\hline $\mathrm{GCOH}$ & 1.432 & 41.40 & 2.27 & 0.90 & 0.52 & 0.92 & 0.717 & 0.534 & 0.777 & 0.910 \\
\hline $\mathrm{H}_{2} \mathrm{O}$ & 1.333 & 78.50 & 1.84 & 1.17 & 0.18 & 1.09 & 1.062 & 0.025 & 0.681 & 0.997 \\
\hline
\end{tabular}

EtOH: Ethanol, DMF: Dimethylformamide, DMSO: Dimethylsulfoxide, THF: Tetrahydrofuran, TCM; Tetra Chloromethane ; TO: Toluene; HX: Hexane; MeOH: Methanol, PrOH: 1-Propanol; DEtR: Diethyl Ether ;Dix: 1,4-Dioxane; EtOAC: Ethylacetate, GCOH, Glycol, ACA: Acetic Acid, AC: Acetone, CHN:Cyclohexanone, CBN: Chlorobenzene, ANO: Anisole, $\mathrm{H}_{2} \mathrm{O}$ : deionized water, $\mu$ : Dipole Moment, $\varepsilon$ : Relative Permittivity, n: Refractive Index.

\section{Result and discussion}

\subsection{The impact of solvent on the electronic absorption spectra}

The steady-state absorbance spectrum of Aniline Violet were measured in nineteen distinctive organic solvents((non-polar, polar protic and polar aprotic solvents) with varying polarities. The solvents utilized, recorded in, Table 1, were chosen in arrange to consider the representation of all sorts of solute-solvent interactions (non-specific and specific solvent effects). The spectroscopic characteristics $\left(\lambda_{\max }\right)$ of Aniline Violet are compiled in, Table 2. The watched changes in UV-Vis absorption spectra recorded for the examined compound in different solvents can be categorized as respectively : (1) absorption crests gotten to be broader which is called solvent broadening, (2) the position of $\lambda_{\max }$ contrasts totally different solvents from the solvatochromism; [21] which can be 
either negative solvatochromism in which the shift within the peak position is subjected to hypsochromic effect(blue shift) or positive solvatochromism in which the shift is bathochromic(red shift), and (3) peak intensity may vary totally different solvents to deliver either hyperchromic effect or hypochromic impact. Superior stabilization of the molecule within the first excited state relative to that within the ground state with expanding solvent polarity, will lead to positive solvatochromism. In this setting, the first Franck-Condon excited state with the solvation design presents within the ground state.[22]

The electronic spectra of the explored compound dissolved in a series of solvents is portrayed in, Figs.2, were found to be surprisingly subordinate on the nature of the solvent, the shorter wavelength band within the UV region of $33333.3-30769.3 \mathrm{~cm}^{-1}$ observed in numerous solvent system is attributed to $\pi-\pi^{*}$ transition (K band) of the benzenoid system present in their structure.[18] However, the $\pi-\pi^{*}$ band for Aniline Violet is blue shifted on going from $\left(v_{\max }=30769.3 \mathrm{~cm}^{-1}\right)$ to $\left(v_{\max }=32786.9 \mathrm{~cm}^{-1}\right)$ with expanding hydrogen bonding ability and polarity of the solvent, when continuing from non polar solvent Toluene $(\pi *=0.54)$ to more polar solvent DMSO $(\pi *=1.00)$, the $\operatorname{dim}$ blue color in DMSO changes to sky blue colour in Toluene, Table 2. This shift is primarily due to solute-solvent interactions that cause stabilization of the $\pi$ orbital more than the $\pi^{*}$ orbital in polar solvents.[23]

Table (2): Electronic absorption spectra of Aniline Violet in presence of protic and nonprotic solvents $\left(\lambda_{\max }, \mathbf{n m}\right),\left(\boldsymbol{V}_{\max }, \mathbf{c m}^{-1} \times \mathbf{1 0}^{-\mathbf{3}}\right)$ and electronic transition energy $(\mathrm{Kcal} / \mathrm{mole})$ at room temperature $\left(\sim 20^{\circ} \mathrm{C}\right)$ and polarity functions used in equation 1.

\begin{tabular}{|c|c|c|c|c|c|c|c|c|c|c|}
\hline Solvents & $\mathbf{f}(\boldsymbol{\varepsilon})$ & $\mathbf{f}(\mathbf{n})$ & $\mathbf{E}_{\mathbf{T}(\mathbf{3 0})}$ & $\boldsymbol{\lambda}_{(\max ) 1}$ & $\boldsymbol{v}_{(\mathbf{m a x}) 1}$ & $\boldsymbol{\lambda}_{(\max ) 2}$ & $\boldsymbol{v}_{(\max ) 2}$ & $\boldsymbol{\lambda}_{(\mathbf{m a x}) 3}$ & $\boldsymbol{v}_{(\mathbf{m a x}) 3}$ & $\mathbf{E}_{(\mathbf{C T})}$ \\
\hline $\boldsymbol{H} \boldsymbol{X}$ & 0.186 & 0.186 & 30.9 & 315 & 31.746 & - & - & - & - & - \\
\hline $\boldsymbol{T C M}$ & 0.226 & 0.204 & 32.4 & 310 & 32.258 & - & - & 600 & 16.667 & 48.3 \\
\hline $\boldsymbol{T O}$ & 0.240 & 0.226 & 33.9 & 325 & 30.769 & 525 & 19.048 & 595 & 16.807 & 48.7 \\
\hline $\boldsymbol{E} \boldsymbol{t} \boldsymbol{R}$ & 0.345 & 0.178 & 34.5 & 320 & 31.250 & 525 & 19.048 & 575 & 17.391 & 50.4 \\
\hline $\boldsymbol{D i \boldsymbol { X }}$ & 0.224 & 0.203 & 36.0 & 300 & 33.333 & 515 & 19.417 & 595 & 16.807 & 48.7 \\
\hline $\boldsymbol{A N O}$ & 0.344 & 0.233 & 37.2 & $305,(\mathrm{w})$ & 32.787 & 555 & 18.018 & 600 & 16.667 & 48.3 \\
\hline
\end{tabular}




\begin{tabular}{|c|c|c|c|c|c|c|c|c|c|c|}
\hline $\boldsymbol{T H F}$ & 0.407 & 0.198 & 37.4 & - & - & $540,(\mathrm{~b})$ & 18.519 & 585 & 17.094 & 49.5 \\
\hline $\boldsymbol{C B N}$ & 0.377 & 0.235 & 37.5 & $305,(\mathrm{w})$ & 32.787 & 545 & 18.349 & 600 & 16.667 & 48.3 \\
\hline $\boldsymbol{E} \boldsymbol{O A} \boldsymbol{C}$ & 0.385 & 0.185 & 38.1 & 305 & 32.787 & 540 & 18.519 & 590 & 16.949 & 49.1 \\
\hline $\boldsymbol{C H} \boldsymbol{N}$ & 0.460 & 0.212 & 39.8 & - & - & $555_{,(\mathrm{b})}$ & 18.018 & 585 & 17.094 & 49.49 \\
\hline $\boldsymbol{A C}$ & 0.464 & 0.180 & 42.2 & 300 & 33.333 & $545,(\mathrm{~b})$ & 18.349 & 585 & 17.094 & 49.5 \\
\hline $\boldsymbol{D M F}$ & 0.481 & 0.204 & 43.2 & $305,(\mathrm{w})$ & 32.787 & $550,(\mathrm{~b})$ & 18.182 & 590 & 16.949 & 49.1 \\
\hline $\boldsymbol{D M S O}$ & 0.484 & 0.221 & 45.1 & 305 & 32.787 & $550^{(\mathrm{b})}$ & 18.18 & 595 & 16.807 & 48.7 \\
\hline $\boldsymbol{P r O H}$ & 0.465 & 0.109 & 50.5 & 310 & 32.258 & $550_{,(\mathrm{b})}$ & 18.18 & 580 & 17.241 & 49.9 \\
\hline $\boldsymbol{A C A}$ & 0.388 & 0.185 & 51.7 & - & - & $545,(\mathrm{~b})$ & 18.349 & 585 & 17.094 & 49.5 \\
\hline $\boldsymbol{E t O H}$ & 0.470 & 0.181 & 51.9 & 305 & 32.787 & $555,(\mathrm{~b})$ & 18.018 & 580 & 17.241 & 49.9 \\
\hline $\boldsymbol{M e O H}$ & 0.478 & 0.169 & 55.4 & 300 & 33.333 & $550,(\mathrm{~b})$ & 18.182 & 580 & 17.241 & 49.9 \\
\hline $\boldsymbol{G C O H}$ & 0.482 & 0.206 & 56.3 & 305 & 32.787 & $550,(\mathrm{~b})$ & 18.182 & 585 & 17.094 & 49.5 \\
\hline $\boldsymbol{H} \boldsymbol{H}_{2} \boldsymbol{O}$ & 0.491 & 0.170 & 63.1 & 305 & 32.787 & 535 & 18.692 & 585 & 17.094 & 49.5 \\
\hline
\end{tabular}

Where: $\mathrm{b}=$ Broad, $\mathrm{W}=$ weak

The second band, see Fig.2, watched within the locale of $19.417-18.018 \mathrm{~cm}^{-1}$ for Aniline violet, can be assigned to a $n-\pi *$ transition. The two lone pairs of electrons of the $\mathrm{N}\left(\mathrm{CH}_{3}\right)_{2}$ group in compound. Hence, $n-\pi *$ transitions are anticipated to require put from these nonbonding orbitals to different $\pi^{*}$. The third band observed at longer wavelengths within the run $17.391-16.667 \mathrm{~cm}^{-1}$ it can be attributed to the partly forbidden transition $\left(n-\pi^{*}\right)$. This band born out from the lone pairs of electrons of the nitrogen atoms, is depicted as a charge transfer band(CT) corresponding to formation of intramolecular and intermolecular hydrogen bonding, charge transfer within the instant of solvent-solute interactions and the interactions between the lone-pairs in molecule and solvents.[24] The charge-transfer nature of this band is deduced from its broadness as from the sensitivity of its $\lambda_{\max }$ to the sort of substituent. This band acquires an appreciable shift towards lower energy (red shift) when the substituent's are electron acceptor because it compared with the cases where the substituent's are electron donor.[25] The hypsochromic shift (i.e. negative solvatochromism) observed with increasing the polarity of solvent. This effect was attributed to the interaction of non polar solvents with nonbonding electron pair of nitrogen atom within the investigated compound. [26] This may be explained by the actual that $\mathrm{n}$ orbitals are more stabilized by hydrogen bonding or polar solvents than $\pi^{*}$ orbitals. [27] 


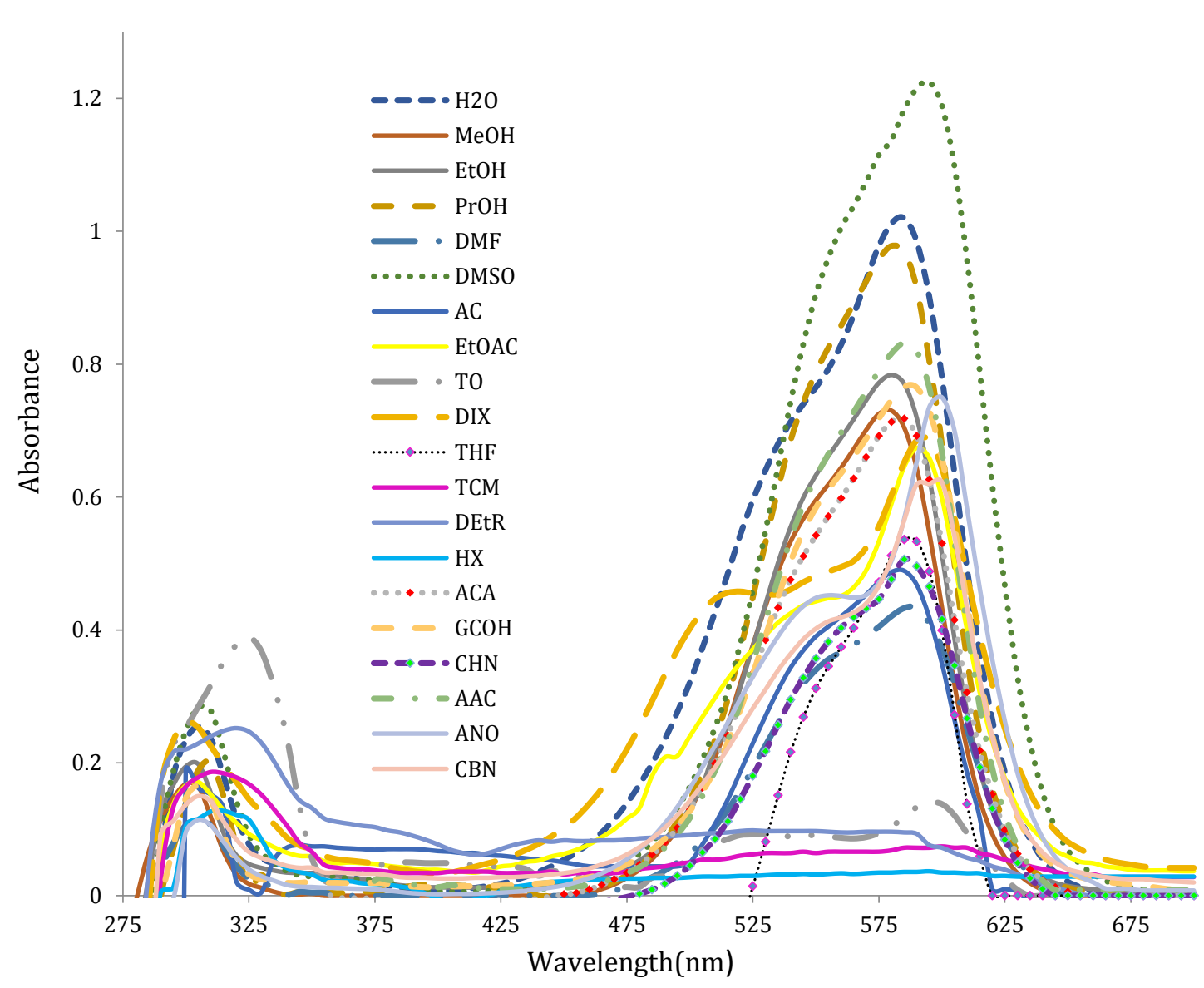

Figure 2: The Spectrum of Aniline Violet in presence of different solvents.

As it will be seen, the most band of Aniline violet located within the spectral range of $17.391-16.667 \mathrm{~cm}^{-1}$, exhibits a lucid shift towards shorter wavelengths in numerous solvents in step with the sequence: $\mathrm{EtOH}<\mathrm{MtOH}<\mathrm{H}_{2} \mathrm{O}<\mathrm{DMF}<\mathrm{DMSO}<$ Anisole $\sim \mathrm{CTC}$. This shift doesn't consider with the change within the polarity of the organic solvents and, therefore, it may be considered as a results of combination of several solvent characteristics like polarity, basicity, and H-bond-accepting ability.

The intensity of the absorption spectra of Aniline Violet depends on the character of solvent, Fig. 2. The absorption intensity of Aniline Violet was found to be highest in polar aprotic DMSO while lowest in polar protic methanol. The low absorption intensity in methanol may be because of the presence of solvent-solute interactions like hydrogen bonding. [28] Since in protic media the n-electrons are involved in intermolecular hydrogen bonding and consequently their excitation is difficult due to their blocking by protic solvent molecules.[29] 
The doublet structure of the AV absorption band in the different solvents, we suggest that the "free" cation degeneracy ( $\mathrm{E}$ state) is perturbed differently depending on the environment of the dye. In a non-polar solvent such as Anisole, AV salt likely exists as ion pairs in solutions whereas in a polar solution such as methanol, all of the ions are solvated.[30] In polar solvents the magnitude of the splitting between the overlapped absorption band of Aniline Violet dependent on the solvatochromic properties of the media, this suggest that the existence of specific interactions [31]

In order to grasp general solvent effects on spectral properties of Aniline Violet, their absorption were plotted as a function of dielectric constant, Fig.3. This polarity parameter (ع) is one among only empirical solvent parameters and sometimes is a quantitative parameter for measuring solvent polarity effects.[5] consistent with Fig.3, the position of low energy band of Aniline Violet is plagued by changing solvent polarity. By increasing the dielectric constant, the position of maximum absorption shifts towards the shorter wavelength. However, spectroscopic behavior of Aniline Violet show some diversity in numerous solvents. The positive value of the slope which suggest that hypsochromic shift.

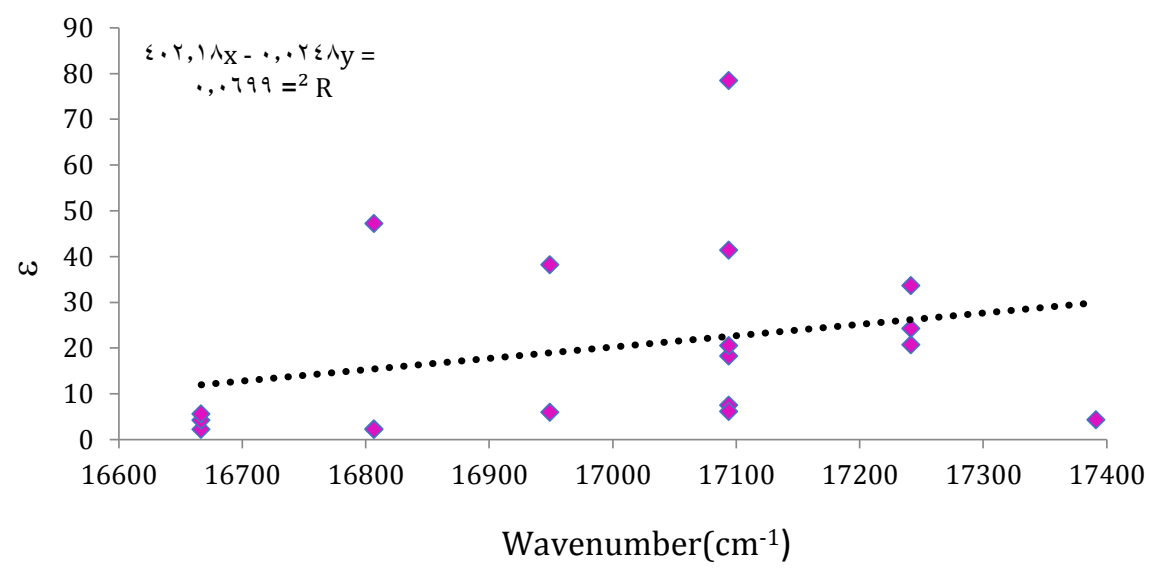

Fig.3: Maximum absorption changes of Aniline Violet by increasing of dielectric constant of used solvents.

\subsection{Multiparametric Solvent Polarity Scales}

It was found that absorption frequencies of Aniline Violet in selected solvents show satisfactory correlation with $\pi *, \beta$ and $\alpha$ similarly like SdP, SP, SB and SA parameters. 
However, the multivariate regression analysis of the $v_{\max }$ data using the Kamlet-Taft model within which non-specific solvent effects are included in single parameter $\pi^{*}$, ends up in, a smaller correlation quality (R) and/or smaller number of solvents (n) which are included in correlations. The advantage of Catalan solvatochromic model stems from the separation of non-specific interaction on polarity and polarizability solvent effects. Because it can see from, Table 3. On a scrutiny of the results in, Table 3 one notices that the magnitudes of the correlation coefficients, it emerges that the HBA Basicity parameter (b coefficient) contributes the most to the $v_{(\max )}$ value in both Catalán $(0.338)$ and Kamlet-Taft (0.488)relations. In contrast, the contribution of the HBD Acidity parameter (a coefficient) is significantly lower than the HBA basicity parameter for both Catalán (0.132) and Kamlet-Taft (0.220) relations. These observations clearly attest to the bare of Aniline Violet which undergo stabilization via hydrogen bonding with the solvent molecules. This suggests that the hydrogen bond accepting (HBA) ability of the solvent affects the transition energy to a greater extent than its hydrogen bond donor (HBD) ability.[32]

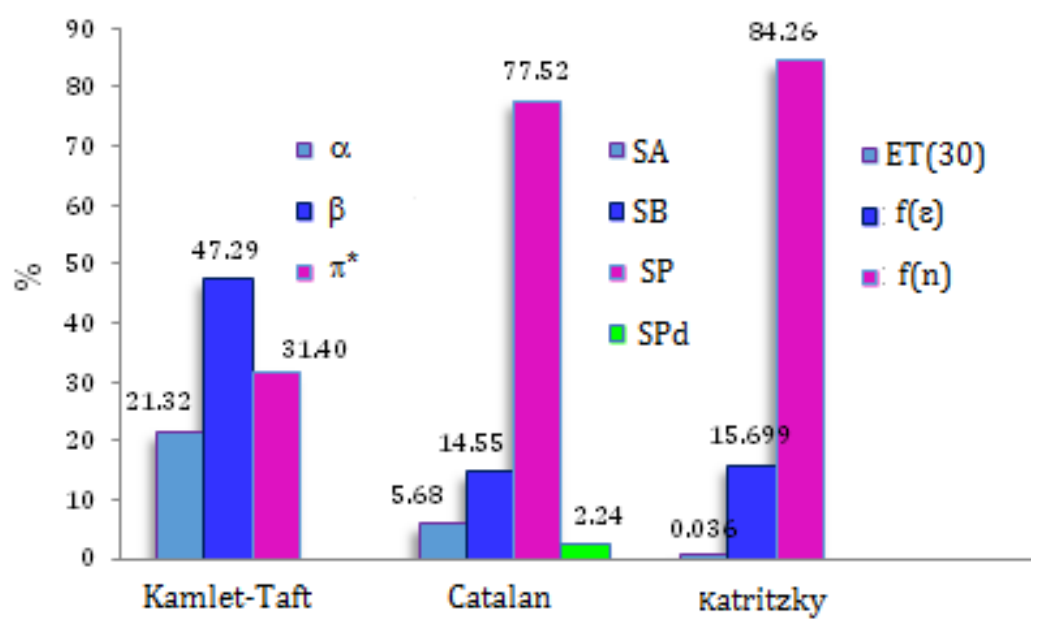

Figure 4: Contribution of solvatochromic parameters: (a) Kamlet-Taft Eq. (b) Catalán Eq. (c) Katritzky Eq.

The nature of Aniline Violet is further corroborated by the actual fact that the polarizability and dipolarity of the solvents play more decisive role compared to their basicity in determining the general $v_{(\max )}$ values for both Catalán $(\mathrm{c}=1.800$ and $\mathrm{d}=0.052)$ and Kamlet-Taft $(\mathrm{s}=0.324)$ treatments. Notably, 
The influence of solvent polarizability (c coefficient for SP) is seen to be greater than the solvent dipolarity (d coefficient for SdP). From, Table 3, The proportion contribution of solvatochromic parameters, Fig.4, of Kamlet-Taft relation Eq.2 , for the investigated compound, showed that the foremost of the solvatochromism is because of solvent hydrogen-bond basicity instead of on dipolarity/polarizability and also the hydrogenbond acidity. In contrast, The percentage contribution of solvatochromic parameters, of Catalan relation, Eq.3, it can seen from, Fig.4, Aniline Violet showed that solvent polarizability is that the most vital parameter which influences the absorption frequency shifts. Solvent hydrogen-bond acidity and basicity have a moderate influence on solvatochromism, whereby the effect of solvent basicity features a more significant impact compared with the solvent acidity. Solvent dipolarity, Table 3, features a negligible impact on solvatochromism.

Table 3: Correlation coefficients obtained from Katritzky, Catalán and Kamlet-Taft multi-parametric analysis through the treatment of $v_{(\max 2)}$ values for Aniline Violet in various solvents.

\begin{tabular}{|c|c|c|c|}
\hline $\begin{array}{c}\text { Equations/ } \\
\text { Coefficients }\end{array}$ & Katritzky Equation & Kamlet-Taft Equation & Catalan Equation \\
\cline { 2 - 4 } & & & $18.080 \pm 0.351$ \\
\hline Intercept ${ }^{\wedge} 10^{3}$ & $17.631 \pm 0.420$ & $16.922 \pm 0.125$ & $0.132 \pm 0.12$ \\
\hline $\mathrm{a}^{\wedge} 10^{3}$ & $-0.002 \pm 0.006$ & $0.220 \pm 0.081$ & $0.338 \pm 0.18$ \\
\hline $\mathrm{b}^{\wedge} 10^{3}$ & $0.868 \pm 0.58$ & $0.488 \pm 0.15$ & - \\
\hline $\mathrm{s}^{\wedge} 10^{3}$ & - & $-0.324 \pm 0.17$ & $-1.800 \pm 0.45$ \\
\hline $\mathrm{c}^{\wedge} 10^{3}$ & $-4.659 \pm 1.42$ & - & $0.052 \pm 0.15$ \\
\hline $\mathrm{d}^{\wedge} 10^{3}$ & - & - & 0.897 \\
\hline $\mathrm{R}$ & 0.782 & 0.793 & 13.399 \\
\hline $\mathrm{F}$ & 7.342 & 7.934 & 0.000 \\
\hline $\mathrm{P}$ & 0.003 & 0.002 & 0.112 \\
\hline $\mathrm{SD}$ & 0.151 & 0.148 & 18 \\
\hline $\mathrm{n}$ & 18 & 18 & $\mathrm{P}$ \\
\hline
\end{tabular}

Where a, b and s: coefficients, R: correlation coefficients, F: Fisher number; , P: the probability of variation, n; no of solvents, SD: standard deviation. 
From the analysis of absorption frequencies according to Kamlet-Taft Eq. (2) and Catalan Eq.3, it had been found that the positive sign of $a$ and $b$ coefficients[33] for Aniline Violet, Table 5, indicates a hypsochromic shift with increasing solvent hydrogenbond acidity and hydrogen-bond basicity. This means stabilization of the bottom state relative to the electronic excited state. In other words, the positive sign of b coefficient and a coefficient suggest the formation of solute-solvent hydrogen bonds for both electronic states, which stabilizes them in solvents with low hydrogen bond donating and high hydrogen bond accepting abilities.

The negative sign of ( $s$ and $c$ ) coefficients, indicates a bathochromic shifts with an increasing solvent dipolarity/polarizability, and polarizability parameter for Catalan, which suggests stabilization of the electronic excited state relative to the bottom state. this is often, in good agreement with the results reported in ref. [34]. Hence, by increase of positive parameters in Eq. (2), the energy difference between ground and excited state is increased and ground state is stabilized.[34], from Table 3, it's emerge the positive sign of $\mathrm{d}$ coefficient which indicates a hypsochromic shifts with increasing solvent dipolarity.

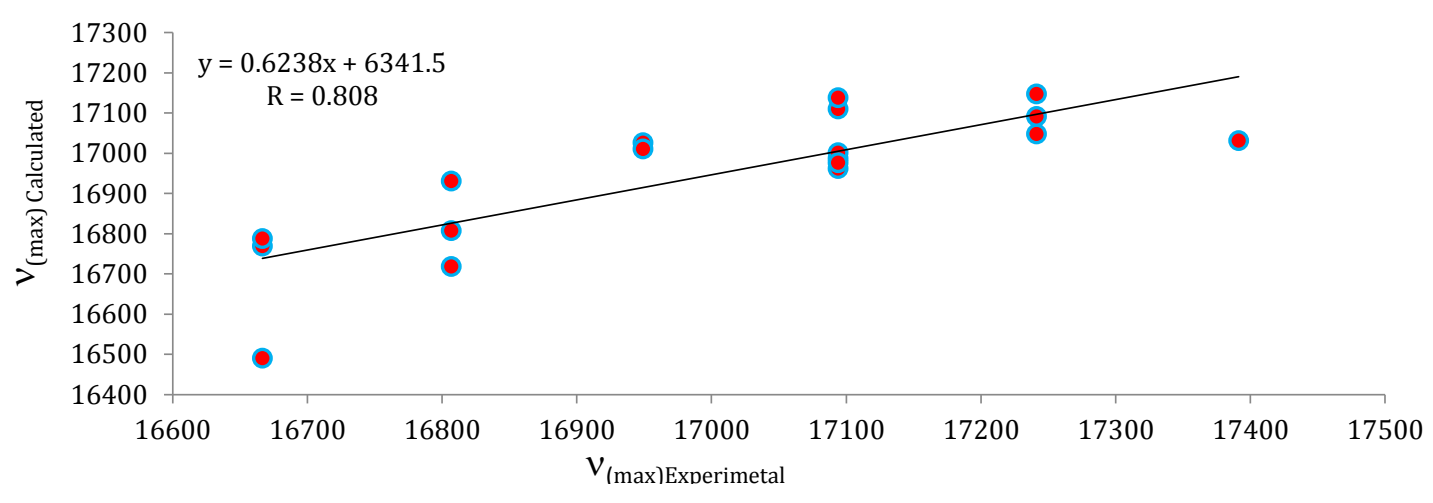

Figure 5: Plot of calculated absorption maxima versus experimental values for AV in different solvents using Katritzky method, (Eq.1)

As it are often seen from Table3, KTZ Eq.1 multi-parameter correlation shows that, for absorption data, generally, the worth connected with $\mathrm{E}_{\mathrm{T}(30)}$ because the lower effectiveness. It is in agreement with the results obtained from KAT and CTN correlations. 
One can observe that the $f(n)$ includes a way more pronounced effect than the $f(\varepsilon)$ to hypsochromic shifts, see Fig.4, because the contribution of the orientation induction interactions to the frequency shift are strong than the dipolar interaction. The positive and low magnitude of dipolar function indicates the hypsochromic shift with an increasing the dipolarity of the solvent this good agreement with CTN results. In contrast, the negative and better magnitude value for $\mathrm{f}(\mathrm{n})$ that's emerge bathochromic shift. This bathochromic shift correspond to more stabilized excited state as compared to the bottom state.

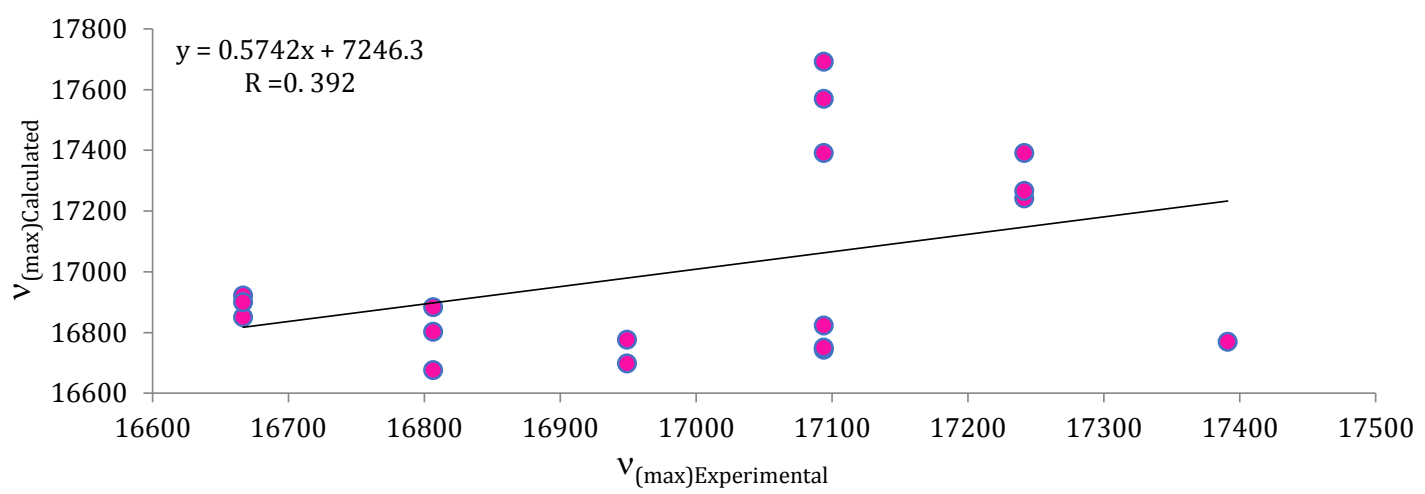

Figure 6: Plot of calculated absorption maxima versus experimental values for AV in different solvents using Kamlet-Taft's method, (Eq.2)

For a far better idea on which of the LSERs between Katritzky, Catalán and Kamlet-Taft is a stronger multiparametric strategy for the solvatochromic data of the investigated compound, linear correlations between calculated and experimentally determined $v_{(\max )}$ values were attempted, Figs.5, 6 and 7 with the positive values of slope. The linearity of the curves is directly correlated to the multi-linear regression quality ( $R$, Table 5) it absolutely was found that these correlations and most of the solvents obeyed the correlation, the rise within the $\mathrm{R}$ and $\mathrm{F}$ values indicates the fitness of the regression model. The correlation coefficients $(\mathrm{R})$ is over 0.50 for linear solvation energy relationship (LSER), indicating the prime quality of the multi-parametric Eqs.(1, 2 and 3), while the coefficient of correlation $(\mathrm{R})$ for Catalán strategy considerably higher than Kamlet-Taft strategy and Katritzky strategy. Therefore, the upper Fisher number, F, the more adequate the corresponding model. 
The F-number for the Kamlet-Taft model is (7.934) and Katritzky model is (7.342) while that of Catalán model is (13.399). Therefore, solvent Catalán scale presents a more robust determination of specific interactions than the Kamlet-Taft scale and Katritzky scale.

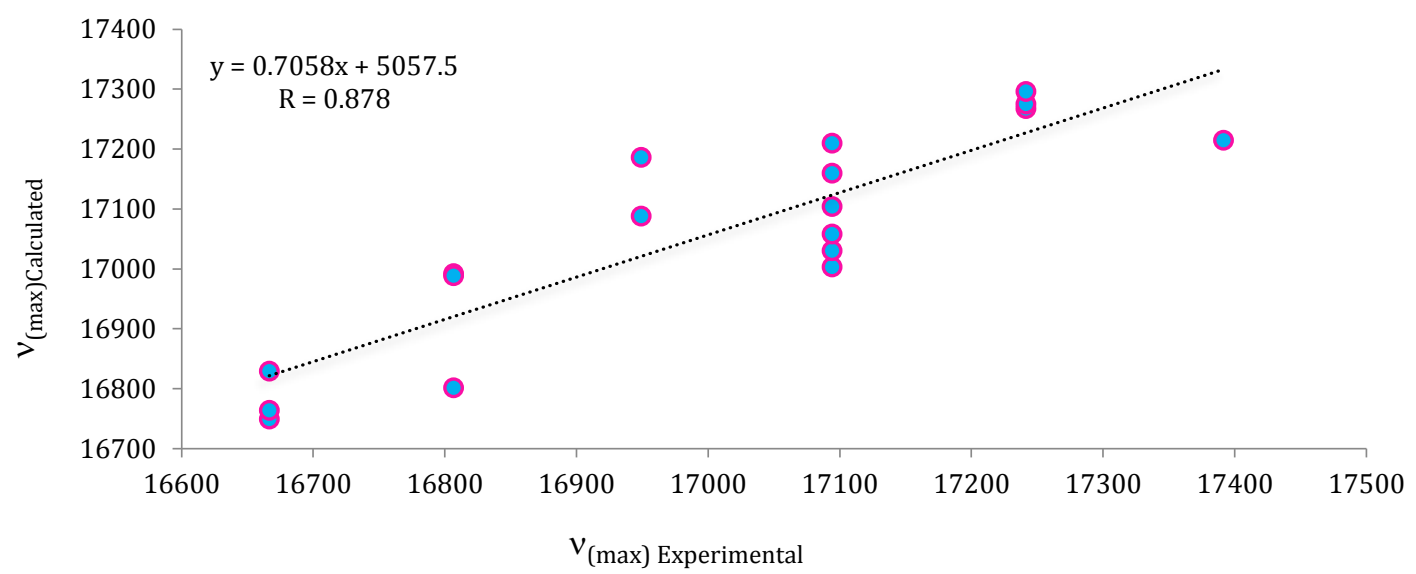

Figure (7): Plot of calculated absorption maxima versus experimental values for AV in different solvents using Catalan method,( Eq.3)

\subsection{The impact of pH on the electronic absorption spectra and estimation of it's pKa}

The electronic absorption spectra of Aniline Violet indicator under investigation at various $\mathrm{pH}$ 's values indicated that the intensity and also the band position are $\mathrm{pH}$ dependence and an isosbestic point was observed. Presumably, thanks to the rearrangement of the molecule and also the ionization of the $\mathrm{NH}\left(\mathrm{CH}_{3}\right)_{2}$ groups, Fig.8, The formation of an isosbestic point had been taken as an indication of the existence of a an equilibrium between two absorbing species.[35] $\mathrm{AV}^{+}$is taken into consideration because the is also a tri-phenyl methane derivative that which a tautomeric and $\mathrm{pH}$ dependent equilibrium exists between tri-phenyl-methyl cation (I) and its quinoidal form (II), Fig.(9).[2] Under protonation, the quinoidal form winds up in formed mono and dicationic forms by protonation on the nitrogen atoms(III and IV)[36], Fig(9). In solution, its colour ranges from blue in strong acidic solutions through blue-violet in weakly acidic (is associated to the modification of the $\pi$ system delocalization pattern) and neutral solutions to purple-violet in alkaline one. 
The color is modified to light violet in strong alkaline medium, in $\mathrm{pH}=12$ transformation color change from light violet to colorless in few minutes this attributed to carbinol base is made .

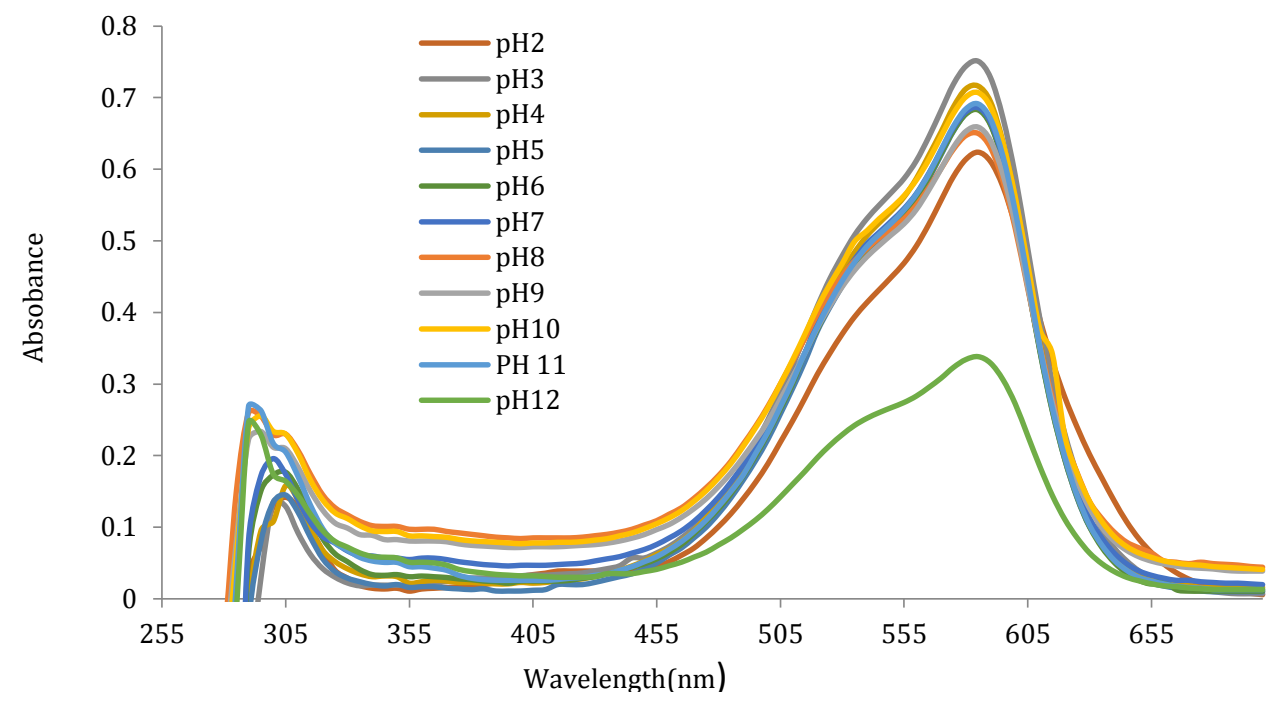

Figure (8): The electronic absorption spectra of $1 \times 10^{-5} \mathrm{M}$ solution of AV in ethanol at different $\mathrm{pH}$ 's.

The electronic spectra of $1 \times 10^{-5} \mathrm{M}$ solution of Aniline Violet in $(50 \%(\mathrm{v} / \mathrm{v})$ ethanol - water solution), within the $\mathrm{pH}$ range (2-12) Fig.8, showed two well-defined bands, the primary band in the range $290-305 \mathrm{~nm}$ ( $\mathrm{n}-\pi^{*}$ assigned to $\mathrm{N}\left(\mathrm{CH}_{3}\right)_{2}$ groups), and centered at $585 \mathrm{~nm}\left(\mathrm{n}-\pi^{*}\right.$ assigned to CT nature formed through the conjugation between the aromatic rings systems via the $\mathrm{C}$ atom link). For acidic solution $(\mathrm{pH} \leq 4)$, the primary absorption bands are lowest in intensity with change in position while the second band are highest in intensity with no change in position suggesting that the unstable form $\left(\mathrm{H}_{2} \mathrm{In}^{+3}\right)$ is deprotonated giving the species $\left(\mathrm{HIn}^{+2}\right)$, Fig.9, $\left(\mathrm{pKa}_{1}=3.82\right)$. However, on increasing the $(\mathrm{pH} \geq 5)$, the second absorption bands remain at the identical position with hypochromic shift in intensity. The spectrum of solutions forming an isosbestic points at 515 and $610 \mathrm{~nm}$ indicating the equilibrium between over one species of the protonated kinds of AV, Fig.9. 

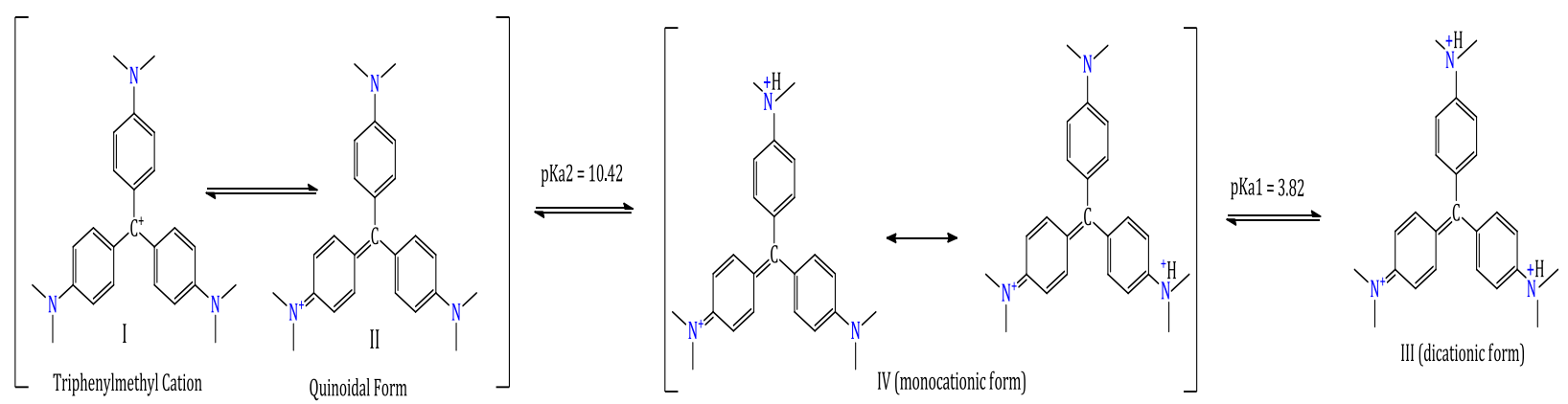

Figure (9): The dissociation mechanism of Aniline Violet

The electronic spectral data at different $\mathrm{pH}$ 's values used to estimate the dissociation constant of the indicator. Three different spectrophotometric methods are applied to calculate the pKa values. The half height, the modified limiting absorption and colleter [36] methods-as modified for acid-base equilibrium- which gave concordant results, Table 4. within the half-height method the pKa values were evaluated at constant wavelength from the half-height of the absorbance, As versus pH curves, Fig.10, where $\mathrm{pKa}=\mathrm{pH}$ at the half height of the curve.

Table (4): Dissociation Constant of Aniline Violet in numerous Solutions of 50\% Water: $\% 50$ Co-solvents at room temperature $\sim 20^{\circ} \mathrm{C}$, ionic strength $0.5 \mathrm{NKCl}$

\begin{tabular}{|c|c|c|c|c|c|c|c|c|c|c|c|}
\hline \multirow[t]{2}{*}{$\begin{array}{c}50 \% \text { Co- } \\
\text { solvent }\end{array}$} & \multicolumn{2}{|c|}{$\begin{array}{c}\text { Half } \\
\text { height }\end{array}$} & \multicolumn{2}{|c|}{$\begin{array}{l}\text { Modified } \\
\text { limiting } \\
\text { absorption }\end{array}$} & \multicolumn{2}{|c|}{ Colleter } & \multicolumn{2}{|c|}{ Average $\mathrm{pKa}$} & \multicolumn{2}{|c|}{$\begin{array}{c}\mathrm{n} \text { (number of } \\
\text { protons ionized) }\end{array}$} & \multirow[t]{2}{*}{$\begin{array}{c}\varepsilon(\text { mediu } \\
\mathrm{m})\end{array}$} \\
\hline & $\begin{array}{c}\text { pka } \\
1\end{array}$ & pka2 & pKa1 & pKa2 & $\begin{array}{c}\mathrm{pKa} \\
1\end{array}$ & $\begin{array}{c}\mathrm{pKa} \\
2\end{array}$ & pKa1 & $\mathrm{pKa} 2$ & & & \\
\hline $\begin{array}{c}1,4- \\
\text { Dioxaine }\end{array}$ & $\begin{array}{c}5.0 \\
0\end{array}$ & $\begin{array}{c}11.4 \\
0\end{array}$ & 4.60 & 10.80 & - & $\begin{array}{c}11.4 \\
5\end{array}$ & $\begin{array}{c}4.80 \pm 0 . \\
28\end{array}$ & $\begin{array}{c}11.22 \pm \\
0.36\end{array}$ & 0.62 & 0.46 & 40.36 \\
\hline DMF & $\begin{array}{c}2.6 \\
0\end{array}$ & 9.70 & 3.10 & 9.40 & 2.37 & 9.41 & $\begin{array}{c}2.69 \pm 0 . \\
37\end{array}$ & $\begin{array}{c}9.50 \pm \\
0.17\end{array}$ & 0.72 & 0.54 & 58.13 \\
\hline $\mathrm{EtOH}$ & $\begin{array}{c}3.7 \\
0\end{array}$ & $\begin{array}{c}10.5 \\
0\end{array}$ & 3.80 & 10.10 & 3.95 & $\begin{array}{c}10.6 \\
5\end{array}$ & $\begin{array}{c}3.82 \pm 0 . \\
13\end{array}$ & $\begin{array}{c}10.42 \pm \\
0.28\end{array}$ & 1.08 & 0.56 & 51.40 \\
\hline $\mathrm{MeOH}$ & $\begin{array}{c}4.3 \\
0 \\
\end{array}$ & $\begin{array}{c}10.9 \\
0\end{array}$ & 4.60 & 10.40 & 4.10 & $\begin{array}{c}10.3 \\
3 \\
\end{array}$ & $\begin{array}{c}4.33 \pm 0 . \\
25\end{array}$ & $\begin{array}{c}10.54 \pm \\
0.31\end{array}$ & 0.60 & 0.50 & 56.10 \\
\hline
\end{tabular}


In the modified limiting absorption method, Fig.11, the pKa values were evaluated by applying the subsequent equation:

$$
p H=p K a+\log \gamma+\log \frac{A-A_{\min }}{A_{\max }-A}
$$

Where $\mathrm{A}_{\max }$ is that the maximum absorption, $\mathrm{A}_{\min }$ is that the minimum absorption, $\mathrm{A}$ is the absorption at any $\mathrm{pH}$ and $\gamma$ is activity coefficient term. By plotting the log absorbance ratio versus $\mathrm{pH}$, a straight line was obtained with a slope giving the quantity of ionized protons. When log absorbance ratio term equals zero, $\mathrm{pKa}=\mathrm{pH}$.

Finally, within the Colleter method, the pKa values were evaluated, where three different concentrations of hydrogen ions were selected and their absorbance values got, $[\mathrm{H}+]_{1}>$ $[\mathrm{H}+]_{2}>[\mathrm{H}+]_{3}$ and $\mathrm{A}_{1}>\mathrm{A}_{2}>\mathrm{A}_{3}$. The acid dissociation constant is calculated:

$$
\begin{gathered}
K=\frac{\left[H^{+}\right] 2-M\left[H^{+}\right] 3}{M-1} \\
M=\frac{A_{3}-A_{1}}{A_{2}-A_{1}} * \frac{\left[H^{+}\right] 1-\left[H^{+}\right] 2}{\left[H^{+}\right] 1-\left[H^{+}\right] 3}
\end{gathered}
$$

Calculations at $585 \mathrm{~nm}$ using the three mentioned spectrophotometric methods reveal only two pKa's ( $3.82 \pm 0.13$ ) and (10.42 \pm 0.28$)$. The $\mathrm{pKa}_{1}$ value (3.82) is attributed to the dissociation the proton of the primary- ${ }^{+} \mathrm{NH}\left(\mathrm{CH}_{3}\right)_{2}$ group of the $\mathrm{H}_{2} \mathrm{In}^{+3}$ form. However, the other $\mathrm{pKa}_{2}$ value (10.42) is attributed to the dissociation of proton of the second${ }^{+} \mathrm{NH}\left(\mathrm{CH}_{3}\right)_{2}$ group of the $\mathrm{HIn}^{+2}$ form to formation neutral form , $\left(\mathrm{HIn}^{+2} \leftrightarrow \mathrm{In}^{+}\right)$. Moreover, the calculated number of ionized protons within the second step is $\sim 0.56$ which supports the suggestion that the mechanism of deprotonation of $\left(\mathrm{HIn}^{+2}\right)$. For the sake of completion, the estimated $\mathrm{pKa}$ values of Aniline violet are indeed 5.31 and 8.64, indicated that this compound will exist almost entirely in the cationic form in a very wide selection of $\mathrm{pH}$ values through the literature. [37] 


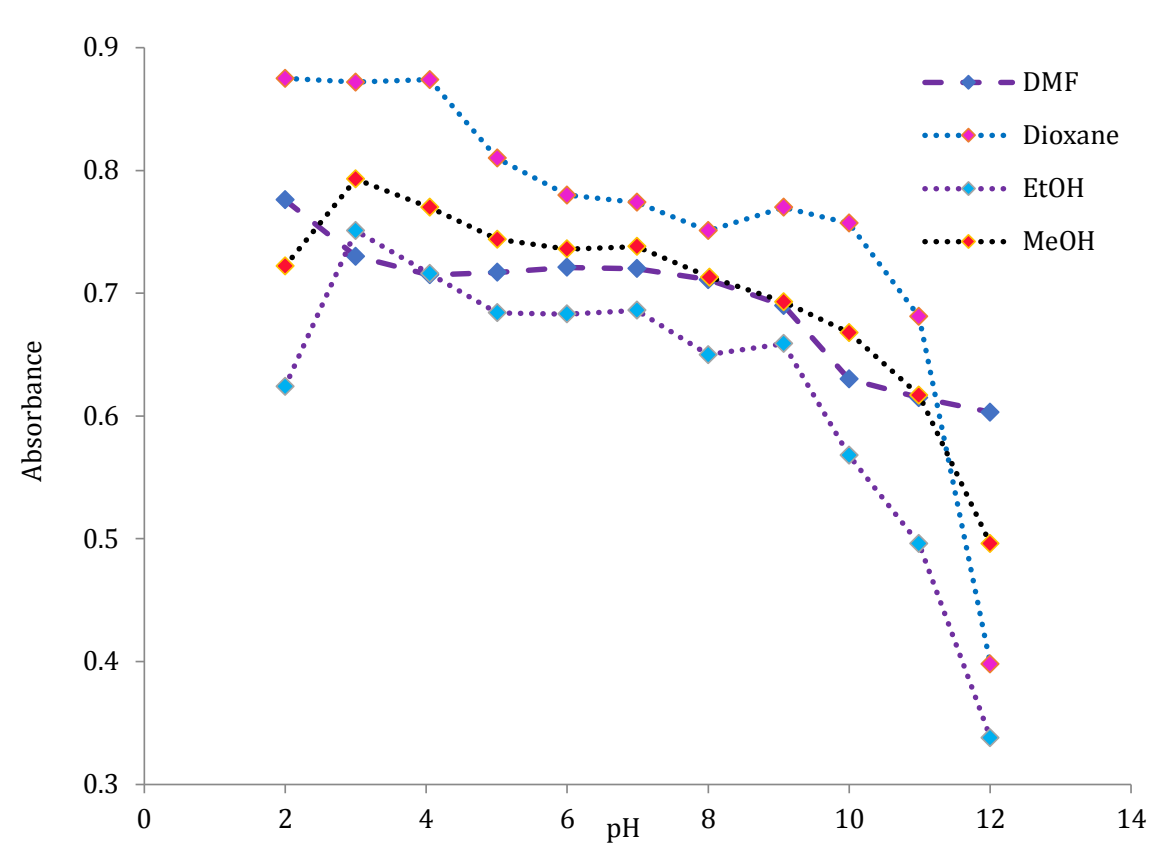

Figure (10): The half height method; Absorbance versus $\mathrm{pH}$ curve of $\mathrm{AV}$ at $\lambda \max$ $=585 \mathrm{~nm}$ in four different solutions

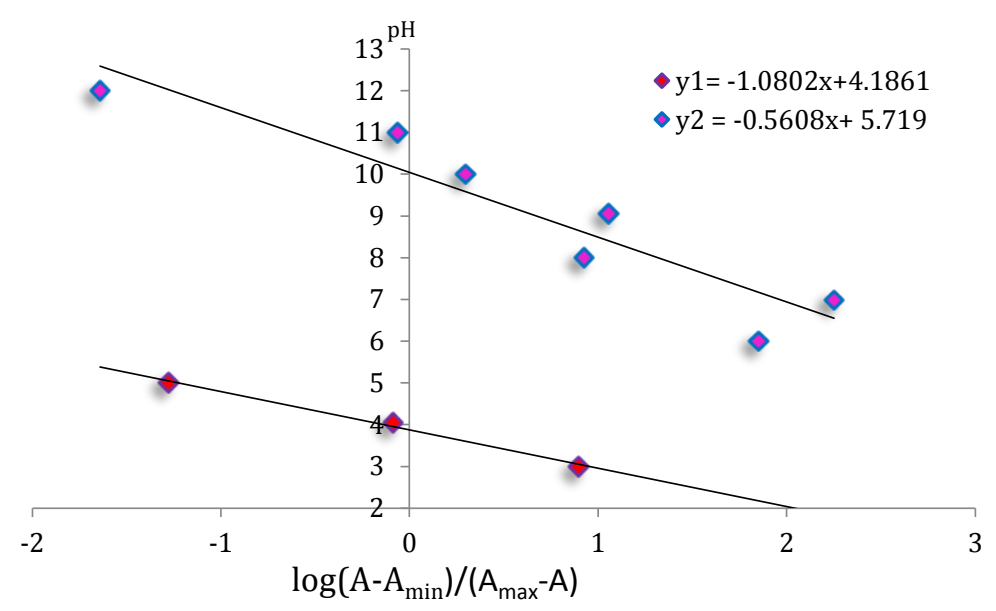

Figure (11): Modified limiting absorption method; $\log$ absorbance ratio versus $\mathrm{pH}$ of $\mathrm{AV}$ at $\lambda=585 \mathrm{~nm}$ in Ethanol: Water Mixture

\subsection{The impact of Co-solvents on the acid dissociation constant of Aniline violet}

The pKa values of the Aniline Violet investigated in several media. It is widely clear from the info gathered in, Table 4. That the pKa values of Aniline Violet is largely dependent on the character of the organic co-solvent. Interestingly, despite methanol and DMF have approximately similar relative permittivity constants (33.7and 38.25, respectively, at $\sim 20$ 
$\left.{ }^{\circ} \mathrm{C}\right)$, the Aniline Violet more acidic in $(50 \% \mathrm{v} / \mathrm{v})$ water $+\mathrm{DMF}$ than $(50 \% \mathrm{v} / \mathrm{v})$ water + methanol (Tables 4). Moreover, although ethanol have lowest relative permittivity (24.28, at $\sim 20^{\circ} \mathrm{C}$ ) than methanol, the dissociation constant ( $\mathrm{pKa}$ ) is approximately in methanol more than the ethanol attributed not only relative permittivity control the magnitude of acid dissociation constant, as results as other parameters of solvents affecting on the worth of dissociation constant $\mathrm{pKa}(38)$. Beside, the relative strength of hydrogen bonding as reflect the difference in pKa values (39). Therefore, as compared despite 1,4Dioxane have approximately the bottom relative permittivity constant $\left(2.22\right.$ at $\left.\sim 20^{\circ} \mathrm{C}\right)$, the Aniline Violet more basic in $(50 \% \mathrm{v} / \mathrm{v})$ water $+1,4-$ Dioxane instead of all solutions.

In general, the pKa values of Aniline Violet in water + organic solvent are arranged in line with the subsequent sequence: $\mathrm{DMF}<\mathrm{EtOH}<\mathrm{MeOH}<1$,4-Dioxaine. $\mathrm{T}$ his order not consider with decreasing the relative permittivity in step with the equation given by Denison and Ramesy [40] and Gilkerson [41] which relates the variation of the pKa of the acid with the relative permittivity of the medium $\varepsilon$. The relative permittivity of water + organic solvent mixtures, $\varepsilon$, was obtained using the subsequent equation. [42]

$$
\varepsilon=\varepsilon_{1} m_{f(w)}+\varepsilon_{2} m_{f(s)}
$$

Where $\varepsilon$ is the relative of water + organic solvent mixtures, $\varepsilon_{1}$ and $\varepsilon_{2}$ are the relative permittivity of the water and organic solvent, respectively, $\mathrm{m}_{\mathrm{f}}$ is the mole fraction, and the subscripts $\mathrm{w}$ and s refer to water and organic solvent, respectively.

In general, effects like hydrogen bonding, solvent basicity, dispersive forces, and protonsolvent interactions play vital roles in the ionization process of acids within the presence of organic solvents [43]. Thus, the observed increase within the pKa of the compound because the change of the organic co-solvent within the medium is increased may be ascribed, additionally to the electrostatic effect, to the hydrogen bonding interaction between the conjugated base $\left(\mathrm{A}^{-}\right)$and solvent molecules. Since water molecules have the next tendency to donate hydrogen bonds than other solvent molecules [44], 
This can tend to extend the pKa value of the compound, as Eq. (4) implies. It indicates also that the difference within the stabilization of the ionic form by hydrogen-bond donor solvent molecules plays a very important role within the increase of the pKa values.

Examination of the results depicted in, Table 4, reveals that the pKa values within the presence of the poorer hydrogen-bond donor DMF are less than those obtained in the presence of corresponding amounts of the other solvents. This behavior may be ascribed to the high basic character of DMF, which reflects itself within the construction of a powerful hydrogen-bond acceptor from the $\mathrm{N}^{+} \mathrm{H}\left(\mathrm{CH}_{3}\right)_{2}$ group of the non-ionized dye molecule and consequently promotes the ionization process (i.e., low $\mathrm{pKa}$ ).

\subsection{Distribution of species at different $\mathrm{pH}$ values}

In the distribution diagrams, a plot the fraction of an acid species versus how that fraction varies with $\mathrm{pH}$ was made, Fig. 12. The variation of the species is due to the acid dissociation shifting as $\mathrm{pH}$ changes [45]. From these diagrams, the prevailing acid species (undissociated acid or any acid anion) at any $\mathrm{pH}$ range could be judged. It is of interest to note that in many cases an intermediate acid anion can never be found as an only species at any $\mathrm{pH}$ range. For Aniline Violet $\left(\mathrm{H}_{2} \mathrm{In}^{+3}\right)$, the $\mathrm{pKa} 1=3.82 \pm 0.13$, Table 4 , could be explained by the deprotonation of Aniline Violet under acidic condition forming $\left(\mathrm{HIn}^{+2}\right)$ (Fig.9). The $\mathrm{pKa} 2$ equals $10.42 \pm 0.28$ where $\left(\mathrm{In}^{+}\right)$is formed by the ionization of the proton from the ${ }^{+} \mathrm{NH}\left(\mathrm{CH}_{3}\right)_{2}$ group.

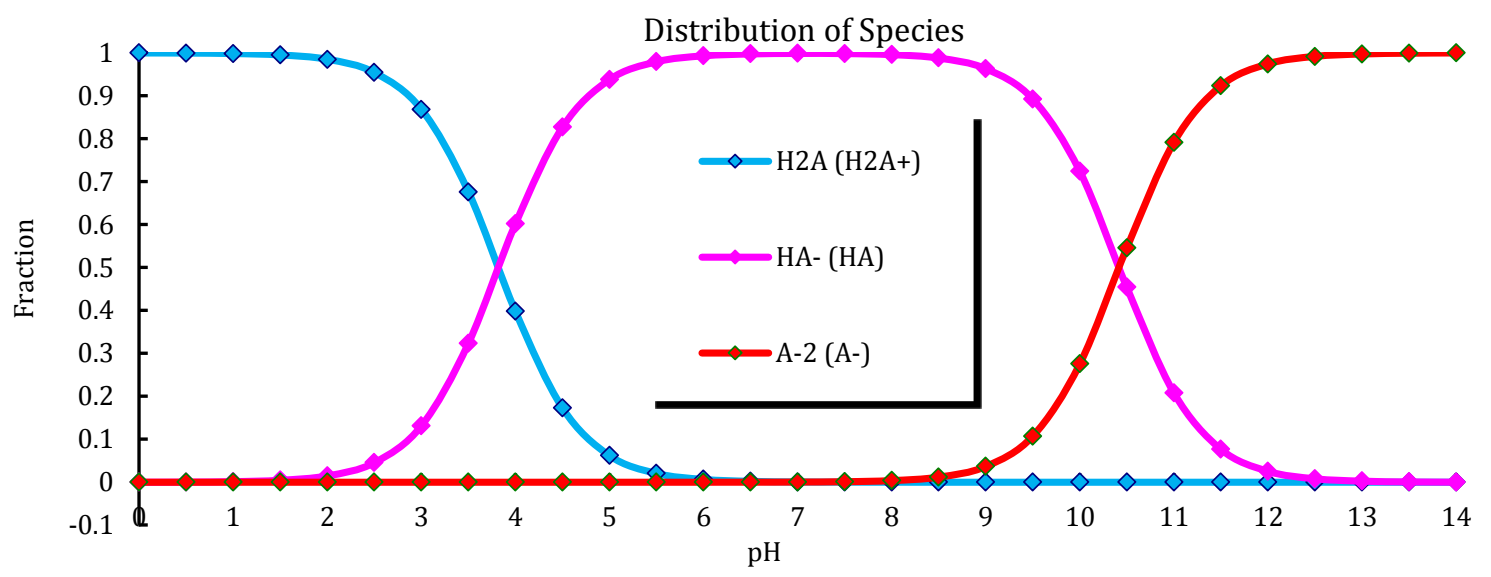

Figure (12): Distribution diagram of the acid species of Aniline Violet indicator in $\% 50(\mathrm{v} / \mathrm{v})$ ethanol: water at different $\mathrm{pH}$ 's. 


\section{Conclusion}

The solvation characteristics of the Aniline Violet molecules were investigated in nineteen solvents of various physical-chemical properties. The steady-state absorption spectral shifts are analyzed using multiple statistical regression model proposed by Katritzky, Kamlet-Taft and Catalan. Thus, correlations (MLR analysis) between wavenumber within the maximum of absorption band ( $\left.v_{\max }\right)$ of this compound and therefore the solvent parameters $\left(\varepsilon, n\right.$ and $\left.\mathrm{E}_{\mathrm{T}(30)}\right),\left(\pi^{*}, \alpha\right.$ and $\left.\beta\right)$ or $(\mathrm{SA}, \mathrm{SB}, \mathrm{SP}$ and $\mathrm{SdP})$. It's been shown that both non-specific (mainly) and specific solute-solvent interactions play roles in solvatochromism of molecule. The results have shown that the absorption maxima of samples are dependent on the solvent polarity and hydrogen bond accepting ability. The $\mathrm{pH}$ effects on the wavenumber of the absorption band maxima of indicator with different constituents were discussed and therefore the mechanism of ionization was explained. The dissociation constant of the investigated compound was resolve by the methods described during this work. The results showed the dissociation constant of Aniline Violet dependence on the relative permittivity of the medium and hydrogen bonding formed between conjugate base and solvent molecule.

\section{Reference}

1) R.W. Sabnis, Handbook of Acid-Base Indicators, CRC Press, Taylor and Francis. 2008, p. 108.

2) J. Barbosa, Indicators, Acid-Base, In Encyclopedia of Analytical Scince (2 ${ }^{\text {nd }}$ Edition), 2005.

3) D.F. Duxbury, The Photochemisry and Photophysics of Triphenylmethane Dyes in Solid and Liquid Media, Chemical Reviews,vol. 93, 1993, pp.381-433.

4) M.S. Zakerhamidi, M. Moghadam, A. Ghanadzadeh, S. Hosseini, Anisotropic and Isotropic Solvent Effectss on The Dipole Moment and Photophysical Properties of Rhodamine Dyes. Journal of Luminescence, vol. 132, 2012, pp.931-937.

5) C. Reichardt, Solvents and Solvent Effects in Organic Chemistry, third edition. Wiley-VCH, Weinheim, 2003. 
6) C. Reichardt, Empirical Parameters of Solvent Polarity as Linear Free-Energy Relationships. Angewandte Chemie International Edition in English, vol.18, 1979, pp. 98-110.

7) E.M. Kosower, An Introduction to Physical Organic Chemistry, Wiley, New York, 1968.

8) C. Reichardt, Solvatochromic dyes as solvent polarity indicators. Chemical Reviews, vol. 94,1994, pp. 2319-2358.

9) C. Reichardt, Pyridinium-N-phenolate Betaine Dyes as Empirical Indicators of Solvent Polarity: Some NewFindings. Pure and Applied Chemistry,vol. 80,2008, pp.1415-1432.

10) V.G. Machado, R.I. Stock, C. Reichardt, Pyridinium-N-phenolate Betaine Dyes. Chemical Review, vol.114,2014, pp.10429-10475.

11)E.M. Kosower, et al., Pyridinium complexes. I. The Significance of The Second Charge-Transfer Band of Pyridinium Iodides. Journal of the American Chemical Society, vol. 82, 1960,pp. 2188-2191.

12)L. E. Vidal Salgado, C. Vargas-Hernández, Spectrophotometric Determination of the pKa, Isosbestic Point and Equation of Absorbance vs. $\mathrm{pH}$ for a Universal $\mathrm{pH}$ Indicator, American Journal Of Analytical Chemistry, vol. 5, 2014, pp.1290-1301.

13) N. Yoshida, M. Fujimoto, Kinetic of The Proton-Transfer Reaction of Some orthoHydroxy Derivative of Azo and Azomethine Compounds in Dioxane-Water Medium, Bulletin of The Chemical Society of Japan, vol.49,1976, pp.1557-1562.

14) N. Yoshida, M. Fujimoto, Kinetic of The Proton-Transfer Reaction of 4-(2,4dihydroxyphenylazo)-nitrobenzene in Dioxane-Water Media, Bulletin of The Chemical_Society of Japan, vol. 50,1977, pp.1328-1332.

15) A.R. Katritzky, D.C. Fara, H. Yang, K. Tamm, T. Tamm, M. Karelson, Quantitative measures of solvent polarity, Chemical Review vol.104, 2004, pp.175198.

16) M.J. Kamlet, J.L.M. Abboud, M.H. Abraham, R.W. Taft, Linear solvation energy relationships. 23. A comprehensive collection of the solvatochromic parameters, $\pi^{*}, \alpha$ and $\beta$, and some methods for simplifying the generalized solvatochromic equation. The Journal of Organic Chemistry, vol. 48 , 1983, pp.2877-2887. 
17)J. Catalán, Toward a Generalized Treatment of The Solvent Effect Based on Four Empirical Scales: Dipolarity(SdP, New Scale), Polarizability (SP), Acidity (SA) and Basicity(SB) of the Medium. Journal of Physical Chemistry Part B, vol. 113,2009,pp. 5951-5960.

18)M.S. Masoud, A. Ali, M. Shaker, M. Abdul Ghani, Solvent and substituent effect on spectroscopical changes of some diazoaminobenzene derivatives, Spectrochimica Acta Part A: Molecular and Biomolecular Spectroscopy, vol. 61, 2005, pp.3102-3107.

19)J.G. Kirkwood, Theory of Solutions of Molecules Containing Widely Separated Charge with Special Application to Zwitterions, The Journal Chemical Physics, 2(7), 1934, 351-361.

20)E.G. McRae, Theory of Solvent Effects on Molecular Electronic Spectra Frequency Shifts, The Journal of Physical Chemistry, vol.61, 1957, pp.562-572.

21)A. Hantzsch, Uber die Halochromie und Solvatochromie des Dibenzal-acetons und einfachere Ketone, Sowie Ihrer Ketochloride. Berichte der Deutschen Chemischen Gesellschaft, vol. 55,1922, pp.953-979.

22)J. Franck, E.G. Dymond, Elementary Processes of Photochemical reactions, Journal of Transaction Faraday Society, vol.21, 1926,pp. 536-542.

23)S. Baliarsingh, S. Patel, B.K. Mishra, Solvent Effect on the Photophysical Behavior of Some Bischromophoric Dyes,2003.

24) I. Sıdır, Y.G. Sıdır, H. Berber, E. Taşal, A study on solvatochromism of some monoazo dye derivatives, Journal of Molecular Liquids, vol. 178 ,2013, pp.127136

25)M. Dakiky, K. Kanan, K. Khamis, Aggergation of O,O'-dihydroxyazo Dyes II. Interaction of 2-hydroxy-4-nitrophenylazoresorcinol in DMSO and DMF. Dyes and Pigments, vol. 41,1999, pp.199-209.

26) M. Ashfaq, R. Saeed, S. Masood, S. Khan, F. Yasmin, Solute-Solvent Interactions of Methyl Violet in Different Solvents on Spectral Data, Russian Journal of Physical Chemistry A, vol. 92, 2018, pp.730-733. 
27) J.W. Robinson, Frame, E.S. and Frame, G.M., II, Undergraduate Instrumental Analysis, Seventh edition CRC Press, 2014.

28)H. Singh, J. Sindhu, J.M. Khurana, Determination of dipole moment, solvatochromic studies andapplication as turn off fluorescence chemosensor of new3-(4-(dimethylamino)phenyl)-1-(5-methyl-1-(naphthalen-1-yl)-1H-1,2,3triazol-4-yl)prop-2-en-1-one. Sensors and Actuators B, vol.192, 2014, pp.536542.

29) A.H. Amrallah, N.A. Abdalla, E.Y. El-Haty, Spectrophotometric Studies on Some Arylazo Barbituric Acids and Arylazo Pyrimidine in Organic Solvents and in Buffer Solutions. Journal of the Chinese Chemical Society, vol. 54, 2007, pp.16291637.

30) J. Korppi-Tommoal, R.W. Yip, Solvent effects on the visible absorption spectrum of crystal viole, Canadian Journal of Chemistry, vol. 59,1980,pp.191-194.

31)L.M. Lewis, G.L. Indig, Solvent Effects on The Spectroscopic Properties of Triarylmeythane Dyes, Dyes and Pigments, vol.46, 2000, pp.145-154.

32)R. Kian, M.S. Zakerhamidi, A.N. Shamkhali, E. Kashani, Study of the variation of intra/intermolecular interactions and configuration of a group of Enone anticancer drugs as a result of solvation, Journal of Molecular Liquids , vol. 274, 2019, pp.114.

33)A. Alimmari, B. Bozic, D. Mijin, A. Marinkovic, N. Valentic, G. Uscumlic, Synthesis, structure and solvatochromic properties of some novel 5-arylazo-6hydroxy-4-(4-methoxyphenyl)-3-cyano-2-pyridone dyes: Hydrazone-azo tautomeric analysis. Arabian Journal of Chemistry, vol. 8, 2015, pp.269-278.

34)S. Yordanova, I. Petkov, S. Stoyanov, Solvatochromism of Homodimeric Styryl Pyridinium Salts. Journal of Chemical Technology and Metallurgy, vol.49, 2014, pp.601-609.

35)M.S. Masoud, M.A. Shaker, A.E. Ali, G.S. Elasal, Solvatochromaticity and pH dependence of the electronic absorption spectra of some purines and pyrimidines and their metal complexes, Spectrochimica Acta Part A: Molecular and Biomolecular Spectroscopy, vol.79, 2011,pp. 538-547. 
36) M. Mehta, B. Mehta, Organic Chemistry , pHI Learning Pvt.td, Second edition, ,2015, p.1079-1080.

37)J. Rojas, D. Suarez, A. Moreno, J.; Silva-Agredo, Torres-Palma, R. Kinetics, Isotherms and Thermodynamic Modeling of Liquid Phase Adsorption of Crystal Violet Dye onto Shrimp-Waste in Its Raw, Pyrolyzed Material and Activated Charcoals, Applied Sciences, vol. 9, 2019, pp.1-18

38)J. Barbosa, C.M. Bosch, V. Sanz-Nebot, Effect of the Solvents on the Equilibria of Acid-Base Indicators in Aprotic and Amphiprotic Solvents; Microchimica Acta,vol. 106,1992,pp. 327-337.

39)J. Stuchr, M.C. Rose, Kinetics of Proton-Transfer Reaction in Aqueous Solution.IV. Broensted Solpe for Internally Hydrogen-Bonded Weak Acids, Journal of the American Chemical Society, vol. 93, 1971, pp.4350-4354.

40)J.T. Denison, J.B. Ramsey, The Free Energy, Enthalpy and Entropy of Dissociation of Some Perchlorates in Ethylene Chloride and Ethylidene Chloride, Journal of the American Chemical Society, vol.77, 1955, pp.2615-2621.

41)W.R. nGilkerson, Application of Free Volume Theory to Ion Pair Dissociation Constants. Journal of Chemical Physics, vol. 25,1956, pp. 1199.

42) N.M. Rageh, Acidity Constants of Some Hydroxy Azo Pyrazolopyrimidines in Mixed Aqueous-Organic Solvents, Journal of Chemical and Engineering Data, vol. 43,1998,pp. 373-377.

43)J.F. Coetzee, C.D. Ritchie, Solute-Solvent Interaction, Marcel Dekker, New York,1969, p. 221.

44)F. Franks, D.J.G. Ives, The Structural Properties of Alcohol-Water Mixtures, Quarterly Reviews, Chemical Society, vol. 20, pp.1966,1-45.

45) A.A. Shoukry, M.M. Shoukry, Coordination Properties of Hydralazine Schiff Base: Synthesis and Equilbrium Studies of Some Metal Ion Complexes, Spectrochim. Acta Part A: Molecular and Biomolecular Spectroscopy, vol.70, 2008, pp.686-691. Copyright (C) 2021 Sokaina Hemdan, Asma Al Jebaly, Fatma Ali, AJRSP. This is an open-access article distributed under the terms of the Creative Commons Attribution

$$
\text { License (CC BY NC). }
$$

DOI: $\underline{\text { doi.org/10.52132/Ajrsp.e.2021.242 }}$ 